\title{
Understanding Community Colleges in the Indian
} Context

\section{Jillian L. Gross}

India will soon have the largest and youngest population in the world, yet less than $20 \%$ of 15 - to 29-year-olds enroll in postsecondary education (Ministry of Human Resource Development [MHRD], 2014). Those who are able to enroll face challenges of quality and relevance in a highly political, largely privatized, and acutely rigid education system (Tilak, 2013). Furthermore, for those who earn a credential, only $15 \%$ are considered employable (Singh, 2012). In an attempt to reform the elite higher education system, policymakers and practitioners promote community colleges as an ideal solution to address issues of access and equity plaguing India's postsecondary education (Agarwal, 2009). Since 1995 , community colleges have spread to every state in the country. Yet, leaders are struggling to establish a sustainable development model because of the effort required to challenge the status quo of an elite, theory-based higher education system.

To date, Indian community colleges (ICCs), framed as "education for employment," have developed in three overlapping phases: first, a nongovernmental organizational (NGO) model operating on the periphery of formal education; second, national expansion through the open education system; and third, incorporation in formal higher and technical education institutions. All share the professed goal of disrupting an inequitable educational system and conform to the globalized concept of a community college by offering flexible postsecondary education to underserved students in a local context (Raby \& Valeau, 2012). Yet, ICCs vary widely in form and function within and between phases. This chapter is intended to serve as an introduction to the complex landscape of ICCs and is based on interviews with Indian policymakers, practitioners, and ICC leaders conducted throughout 2015.

\section{Postsecondary Education in India}

Organized postsecondary education in India is the legacy of an elite exam-based system implemented during British rule now encompassing a rigid and hierarchical four-stream structure that includes higher, technical, vocational, and open/distance education. Only $12 \%$ of students in India complete 12 years of schooling, and there is a $50 \%$ attrition rate at each year of secondary education (MHRD, 2014). Overall, persistent challenges vexing the system include high dropout rates; inequality of

This is the author manuscript accepted for publication and has undergone full peer review but has not been through the copyediting, typesetting, pagination and proofreading process, which may lead to differences between this version and the Version of Record. Please cite this article as doi: 10.1002/cc.20242.

This article is protected by copyright. All rights reserved. 
opportunity based on geography, gender, caste/tribe, socioeconomic status, and religion; and general quality of education (Carnoy \& Dossani, 2013; Tilak, 2013).

Students, parents, and employers often view any credential other than a degree, especially those earned in an industrial training institute or polytechnic, as "second class" in a society that generally views skilled trades as low-status employment (Singh, 2012). Socially and economically marginalized students predominantly pursue these credentials, which critics regularly argue are outdated, low-quality education that rarely leads to sustainable employment (King, 2012). In order to address these inequities, the central government recently began shifting education reform priorities from mere expansion to focus on quality, employability, and accountability (Carnoy \& Dossani, 2013; Tilak, 2013).

Guiding this work is a massive "skilling" campaign that pledges to "bridge the social, regional, gender, and economic divide" (Ministry of Finance, 2013, p. This quote comes from a 2013 press release online that is less than one pg. Retrieved from http://pib.nic.in/newsite/mbErel.aspx?relid=96468) and provide both vertical and horizontal mobility within and between education, training, and the labor market (Ministry of Skill Development and Entrepreneurship [MSDE], 2015). In an attempt to standardize and coordinate activities, a competency-based National Skills Qualification Framework (NSQF) is in the early stages of implementation. This is the first concentrated national push to "vocationalize" education and focus on increasing the employability of students through higher education (MSDE, 2015).

Postsecondary education institutions, motivated by substantial funding opportunities, are beginning to offer new courses aligned with the framework. Higher education officials have even inaugurated modular pathways from ICC through a PhD under the framework; but it is too early to assess how well these programs fulfill the promise of flexibility, mobility, and improved employment prospects.

\section{Community Colleges in India}

The idea of developing a system of junior colleges in India dates back to the 1930s (Odgers, 1933), but these were envisioned to serve as a bridge between lower secondary school and university in the years before compulsory secondary school. It was not until a delegate from the new College of Vocational Studies at the University of Delhi attended the Wingspread Conference on International Education and the Community College in 1978 that education reformers began considering the adaptation of the community college model in India (Yarrington, 1978). It would be more than a decade before the idea began to flourish.

In 1995, Pondicherry University established the country's first community college (Singh, 2012); and Madras Community College, the first NGO ICC, followed in 1996. Although existing institutions such as polytechnics and industrial training institutes also conform to the globalized concept of a community college (Raby \& Valeau, 2012), their terminal curricula and disconnection from the local context left stakeholders seeking an alternative approach (Anand \& Polite, 2010). Therefore, early ICCs were actively promoted as being based on the North American model but "adjusted to meet India's unique needs and aspirations" (Alphonse, 2013, p. 17).

By 1998, Dr. Xavier Alphonse, a Jesuit priest and university administrator, established the Indian Centre for Research and Development of Community Education (ICRDCE) in Tamil Nadu. Over the last 20 years, Alphonse has arguably been the single most influential actor in the growth of ICCs. Through workshops, teacher training programs, and consultations with policymakers, ICRDCE promotes ICCs as a solution to an ailing educational system that largely ignores marginalized students (Alphonse, 2013). Under his leadership, ICRDCE developed hands-on and personal development-oriented curricula that diverged significantly from the heavily theory-based curricula of conventional education in India. With

This article is protected by copyright. All rights reserved. 
ICRDCE helping establish over 300 ICCs in 25 states and steering national ICC policy design (ICRDCE, 2015), the concept gained traction at the state and national levels.

Encouraged by ICRDCE, in 2008, the Tamil Nadu state government adopted progressive policies to promote ICCs (Alphonse 2013). Subsequently, Tamil Nadu Open University has recognized 204 community colleges, and many traditional colleges and universities began establishing NGO ICCs. NGO ICCs largely offer short-term certificate and diploma programs for students without the ability to transfer into degree programs, whereas Open University ICCs are designed to allow vertical mobility within Tamil Nadu Open University only.

Building on the momentum in South India, Alphonse led efforts to establish national recognition for ICCs - the second phase of development. In 2009, after years of advocacy, Indira Gandhi National Open University (IGNOU) established a community college initiative that allowed organizations "rooted in community-based activities" to register as an ICC (IGNOU, 2011, p. 14). The IGNOU policy outlined a curriculum of stackable credentials with the possibility of transfer into an IGNOU degree program (IGNOU, 2011). Within the first 3 years, IGNOU registered over 600 ICCs, many of which were already associated with ICRDCE. IGNOU's network model offered ICCs national recognition without being constrained by the conventional postsecondary education system; but quick expansion without the necessary infrastructure in place left the new program vulnerable.

Almost as quickly as IGNOU ICCs opened, the initiative was discontinued. Despite attempts to monitor the new ICCs, by spring 2012, IGNOU's board of management suspended the program due to a lack of oversight and quality assurance. Two subsequent review committees concluded that the ICCs should continue but would need more rigorous accountability measures. Despite these findings, the board of management, under the leadership of a new vice chancellor, unexpectedly issued a letter discontinuing all IGNOU ICCs as of July 2013. There was legal and political backlash from students and ICCs for this decision and many credentials are yet to be issued.

Simultaneous to the rise and fall of the IGNOU scheme, the central government was planning to expand ICCs into higher and technical education. National planning documents began including the ICC concept as early as 2002, but it was not until the most recent strategic plan (2012-2017) that the Planning Commission (2011) explicitly called for the integration of existing ICCs and the expansion of a multifaceted system "based on the North American Model." Inaugurating the third phase of ICC development, the colleges were to "provide modular credit-based courses with entry and exit flexibility that conforms to the National Skills Qualification Framework" (p. 101).

Hence, the Ministry of Human Resource Development initiated a parallel ICC initiative to be housed within traditional colleges, universities, and polytechnics. ICRDCE and a new prominent player, the Wadhwani Foundation-a Bangalore-based NGO-provided official support. The ministry began funding its new ICCs in late 2013, after years of deliberation, collaboration, and mobilization of policymakers, industry partners, academics, and international collaborators. Seventy-two polytechnics and 64 traditional colleges and universities received funding that year. Rather than creating stand-alone institutions, new ICCs operate much like a small department within an institution, offering new skillbased vocational education credentials in high-growth industries (Suraksha, 2015). With the central government's new prioritization of skill development and educational reform, national efforts to standardize and regulate ICCs began.

\section{ICCs Today.}

To date, there is no centralized database to register ICCs from different founding contexts. This makes it impossible to pinpoint the exact number of

This article is protected by copyright. All rights reserved. 
ICCs given wide variance in definition and implementation; existence of independent ICCs with no affiliation to ICRDCE, IGNOU, or the central government; and overlap in ICCs between each phase of growth. This leaves most ICCs operating independently with little interorganizational awareness or communication and minimal oversight or accountability.

As of January 2016, over 200 ICCs associate formally with ICRDCE, which helped establish and monitor many more (ICRDCE, 2015). ICRDCE is encouraging curricular alignment with the National Skills Qualification Framework, while continuing to promote an NGO ICC model (X. Alphonse, personal communication [The three "personal communication" citations are from interviews I conducted with individuals. I included citations because I did not write the chapter as a research paper. That being said, rather than cite as "personal communication" I would prefer to remove all four citations as is standard with a qualitative research study to protect the confidentiality of my research participants. Father Xavier was the only one who was comfortable with his name being used.]). IGNOU is in the process of formalizing a new scheme to align with the framework and multiple states run ICCs through their state Open University system. Additionally, many former IGNOU ICCs continue their operations autonomously, without official recognition for their programs.

In the third-phase of ICCs initiated by the Ministry of Human Resource Development as of November 2015, the University Grants Commission (UGC) had conducted three selection processes and partially funded more than 200 ICCs in colleges and universities. In addition to the initial 72 ICCs funded at polytechnics, in 2014 the All India Council on Technical Education gave each of its 3,500 institutions an unfunded mandate to train at least 100 students per year under the framework. As the council defines a community college as any technical institution offering at least one course aligned with the framework (Mantha, 2014), this policy effectively renders all of its institutions ICCs, in name if not in practice. As of November 2015, higher and technical education officials were hopeful about the future of ICCS, but funding and political support remain tenuous.

Implementation of the framework, and its centralized oversight by the new Ministry of Skill Development and Entrepreneurship, provides a mechanism for potential convergence among different types of ICCs. Currently, the promise of educational mobility, although thoughtfully incorporated into policy design, is largely unrealized in practice. ICC norms and expectations are generally shared through one-way communications - workshops and the distribution of guidelines-from ICRDCE, IGNOU, and now central government agencies. Generally, there is no meaningful opportunity for feedback, sustained interorganizational activity, or ongoing oversight to ensure consistency or cohesion in implementation. Furthermore, future funding, and therefore the viability of ICCs, is in jeopardy. In light of these opportunities and challenges, ICCs are well positioned to serve as a catalyst for educational, economic, and social reform; but their ultimate form, function, and position within postsecondary education remain uncertain.

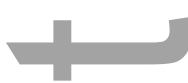

\section{Making Sense of the ICC Landscape}

The key to ICC growth rests in simultaneous strategies to secure local interest alongside regional and national policy support among leaders. Despite the interconnection of these actors, there is no formal feedback mechanism that allows practice to inform policy; no meaningful oversight; and inconsistent expectations among ICC phases. Although Indian community colleges universally offer skill development education to marginalized students, community college practitioners themselves rarely interact. Instead, the concept is largely spread through mandatory workshops rather than professional networks, and participation is stimulated by the lure of government-controlled recognition. Operating in relative

This article is protected by copyright. All rights reserved. 
isolation, college leaders have wide latitude to interpret the concept in practice, leaving implementation fragmented. Course structure and content, eligibility criteria among students, and mobility within postsecondary education and employment are inconsistent among ICCs. Although leaders work to legitimize community colleges at the national level, their efforts are unlikely to ensure organizational viability if policy remains disconnected from practice.

By all anecdotal accounts, the ingredients for ICC success include a leadership team committed to the individual needs of students, faculty committed to nonconventional curricula and teaching methodologies, industry partners committed to providing a high-quality educational experience for students, and students committed to personal development. The result of these commitments, when firmly rooted in the local community, is an equitable partnership that helps students pursue further education and secure sustainable employment with realistic possibilities for upward mobility and lifelong learning. However, ensuring these conditions is no easy task.

The danger of such an intentionally vocational focus, as Brint and Karabel (1989) concluded about U.S. community colleges, lies in the potential for ICCs to serve as a tool to reproduce, rather than ameliorate, social inequalities. In India, this concern is exacerbated by a complex social context informed by an ancient history of caste and a modern history of colonialism. The current reality includes extreme economic disparities, lack of educational opportunity, and a largely unorganized labor market in the world's most populous democracy. Tilak (2013) argues, "The massive program [i.e., skilling] is being planned not as a part of secondary or higher education, but effectively as another tier in the education system that can facilitate segregation of the students into vocational education and higher education" ( $p$. 42). That being said, vocationalization, if aligned with the needs and aspirations of youth over and above the needs of the economy, could help reform a rigid and bureaucratic educational system into a more engaging, inclusive, and equitable experience. Such an effort would make great strides toward enhancing the "social acceptability" of (nonengineering) technical and vocational education.

Because the state alone controls educational certification in India, to secure credibility, ICCs contort themselves to align with a revolving set of government policies that are set with little regard for local implementation. This gives the state significant power over what it means to be an ICC conceptually, but little power over what it means in practice. For example, all ICCs maintain adherence to a norm of employment education, but its enactment varies based on founding context and organizational leadership. As ICC control has shifted from grassroots efforts to state-organized initiatives, the priority of national economic development has begun to overshadow the early goals of student development at the system level. Yet, practitioners at the organizational level have nearly free reign to interpret the concept to satisfy their personal interests, which may complement or compete with changing expectations related to government recognition. Because assessment and funding plans can dramatically shape implementation, how future policies are crafted will be critical to achieving educational justice and the ultimate success or failure of ICCs.

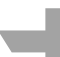 \\ Considerations for Policy and Practice}

According to Indian policymakers and practitioners, aligning education to employment and implementing experiential pedagogies require a change in mindset and practice that cannot be achieved overnight. Transitioning from textbook-based exams to competency-based evaluations demands new learning methods that have been largely absent from postsecondary education. It cannot be overstated that the teachers, trainers, and industry partners being asked to implement new skills-based vocational

This article is protected by copyright. All rights reserved. 
education are themselves the products of the conventional education system. Therefore, increased attention to how teachers and trainers are prepared to accomplish this new work is imperative (Goel, 2015).

Rather than top-down information dissemination, professional development designed to engage participants in collective knowledge sharing could provide valuable opportunities to identify common challenges and opportunities, share problem-solving techniques, and foster postmeeting interaction. Such activities could help develop support structures and create professional standards that reflect the experience of the grassroots level in order to buffer ICCs from an ever-changing parade of policymakers who often have little expertise in education. This conclusion reflects anecdotal evidence from ICC stakeholders and my experience witnessing the power of (relatively rare) opportunities for interaction between ICC leaders. Without the reinforcement of local practitioners, the ICCs' potentially transformative educational approach may wither.

Practitioners generally agree that the most successful implementation of skills courses in ICCs has been the result of dedicated educators putting the individual transformation of students at the core of their work. This means that more than providing employability skills, effective practitioners at the grassroots level are focusing on the holistic development of "responsible citizens" (former IGNOU Vice Chancellor Pillai quoted in Anand \& Polite, 2010, p. 15). In light of this success, prioritizing individual transformation over workforce transformation in future policy and practice could help ensure social justice outcomes rather than the reproduction of an elite system.

Complementary to prioritizing student development, viewing the framework as a baseline to be augmented and adapted in the local context will be imperative. In a country as diverse as India, only a local focus is likely to provide the necessary fit between employer expectations, student learning, and entrepreneurship opportunities. This will help ensure sustainable employment for students with the possibility of upward mobility while providing incentives to employers to hire trained individuals for higher initial wages-primary concerns among skill development leaders.

A final caveat: India is an increasingly attractive site for U.S. community college involvement and both countries prioritize bilateral collaboration. Some examples include the Obama-ingh Knowledge initiative and the U.S.-India Higher Education Dialogues, the United States India Educational Foundation, and numerous U.S. community colleges that have forged independent partnerships across India. In 2013, the American Association of Community Colleges signed a memorandum of understanding (MOU) with the All India Council for Technical Education to support ICC development. Despite concerted efforts from both partners including multiple site visits, this MOU has seen very little progress. To date, differing expectations over funding, institutional selection, and authority to implement, among other challenges, have created seemingly insurmountable roadblocks.

Partnership is often challenging because of differing expectations born out of the vastly different systems. India has a highly centralized system that treats higher, technical, vocational, and open/distance education as distinct streams of postsecondary education with regulated by different agencies along with a nascent and largely voluntary accreditation system. On the other hand, U.S. higher education is a largely decentralized system marked by organizational autonomy, a well-developed accreditation scheme, and a comprehensive approach to postsecondary education. The scale and speed of change possible within each system or within a given institution are markedly different as is the ability to mandate participation (or not). All collaborations should carefully consider contextual differences in a highly political environment. Partnership is likely to be stymied without understanding systematic differences and working to find common ground from which to begin operating. This work requires deep wells of patience, perseverance, and a willingness to learn from each other as much as teach.

This article is protected by copyright. All rights reserved. 


\section{Conclusion}

Because practitioners are isolated, accountability is negligible, and policy decisions are based on anecdotal evidence rather than professional expertise, ICCs are in danger of falling victim to the fickle winds of political and economic change. Yet, powerful reform would be possible with policy design that stimulates knowledge sharing, creates substantive feedback mechanisms, and buffers practitioners from short-term policy and funding concerns. Therefore, the experience of leaders working every day to legitimize ICCs and bring coherence to a disjointed system should be used to elevate the often-silenced voice of practitioners in future policy initiatives. Only by bridging the divide between policy and practice will ICCs fulfill their promise as a meaningful gateway to postsecondary education and employment.

\section{References}

Agarwal, P. (2009). Indian higher education: Envisioning the future. Mumbai, India: Sage Publications.

Alphonse, X.A. (2013). The Indian community college system: Inspiration from community colleges in the United States. In N. Jha (Ed.), The U.S. community college model: Potential for applications in India (pp. 17-22). New Delhi, India: Institute for International Education.

Anand, N. \& Polite, S. (2010). Looking for answers. EDU Tech for Leaders in Higher Education, 1(7), 10-17.

Brint, S., \& Karabel, J. (1989). The diverted dream: Community colleges and the promise of educational opportunity in America, 1900-1985. New York, NY: Oxford University Press.

Carnoy, M., \& Dossani, R. (2013). Goals and governance of higher education in India. Higher Education, 65(5), 595-612.

Goel, A. (2015. July). Seven pillars for national skills policy. Human Capital Magazine. Retrieved from http: //wadhwani-foundation.org/press/seven-pillars-for-nationalskills-policy-ajay-goel-featured-in-human-capital-magazine/

Indian Center for Research and Development of Community Education. (2015, July 15). Role of

ICRDCE. Retrieved from http://www. icrdce.com/roleoficrdce.html

Indira Gandhi National Open University. (2011). Guidelines for community colleges. New Delhi, India: Indira Gandhi National Open University.

King, K. (2012). The geopolitics and meanings of India's massive skills development ambitions. International Journal of Educational Development, 32(5), 665-673.

Mantha, S. S. (2014). National skills qualification framework (NSQF), credit framework, regulations and faculty qualifications [PowerPoint slides]. Retrieved from

http://www.knowyourcollege-gov.in/resources/workshop ppt/Output/37-SS20MANTHA Skills 051214.ppsx

This article is protected by copyright. All rights reserved. 
Ministry of Finance. (2013). Government sets-up the national skill development agency. New Delhi, India: Press Information Bureau, Government of India.

Ministry of Human Resource Development. (2014). Annual report 2013-14. New Delhi, India: Government of India.

Ministry of Skill Development and Entrepreneurship. (2015). National policy for skill development and entrepreneurship 2015. New Delhi, India: Government of India. Retrieved from http://pibphoto.nic.in/documents/rlink/2015/jul/p201571503.pdf

Odgers, G.A. (1933). A junior college movement in India. Junior College Journal, 4(1), 3-7.

Planning Commission, Government of India. (2011). Twelfth five year plan (2012-2017). New Delhi, India: Sage Publications.

Raby, R. L., \& Valeau, E. J. (2012). Educational borrowing and the emergence of community college global counterparts. International Perspectives on Education and Society, 17, 19-46.

Singh, M. (2012). India's national skills development policy and implications for TVET and lifelong learning. In M. Pilz (Ed.), The future of vocational education and training in a changing world (pp. 179-211). Wiesbaden, Germany: Springer.

Suraksha, P. (2015, February). A study on skilling. New Indian Express. Retrieved from http://ww. newindianexpress.com/education/edex/A-Study-onSkilling/2015/02/16/article2665935.ece

Tilak, J. B. G. (2013). India: Reforming education in the neo liberal era. In Y. Wang (Ed.), Education policy reform trends in G20 members (pp. 33-53). Berlin, Germany: Springer.

Yarrington, R. (1978). Internationalizing community colleges. Report of a Wingspread Conference. Washington, DC: American Association of Community and Junior Colleges.

JILLIAN LEIGH GROSS is a doctoral candidate at the University of Michigan, Ann Arbor, in the Center for the Study of Higher and Postsecondary Education.

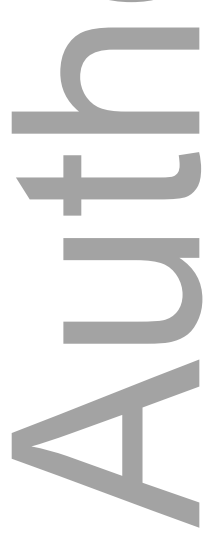

This article is protected by copyright. All rights reserved. 